\title{
INTONATION OF ENGLISH DECLARATIVE SENTENCE PRODUCED BY ENGLISH DEPARTMENT STUDENTS
}

\author{
Rudha Widagsa \\ Fakultas Keguruan dan Ilmu Pendidikan, Universitas PGRI Yogyakarta \\ widagsa@upy.ac.id
}

\begin{abstract}
This research is aimed at finding and describing the intonation of English declarative sentence produced by English Department students of Universitas PGRI Yogyakarta. The intonation is analyzed based on contour approach through the movements of pitch. The researcher uses three students as his respondents. The data are analized through three steps, firstly, data are collected through listening and recording process, secondly, the recording data are converted to soundwave and pitch diagrams using PRAAT software, at this point, PRAAT text grid is applied to make the pitch diagrams easy to understand, and finally, the researcher draws conclusion according to the contour of pitch in the diagrams. The result of this research illustrates that the respondents tend to rise the pitch at end of English declarative sentence which correspondingly changes the mood of the sentence into an interrogrative sentence. English declarative sentences generally have falling intonation and native speakers of English do not rise the pitch at the end of declarative sentences. However, this research shows that students of English have inadequate knowledge about suprasegmental features in English particularly intonation.
\end{abstract}

Keywords: intonation, declarative, sentence

\section{Background}

It is not easy to teach English pronunciation. For many teachers the most problematic area of pronunciation is intonation, most students find it extremely difficult to hear 'tunes' or to identify the different patterns of rising and falling tones as the result, they seem to ignore English intonation. In Indonesia, in the context of English language teaching (ELT), however, pronunciation has not been considered as an important material. Hence, Teaching English in Indonesia is likely focused on grammar and vocabulary, the existence of suprasegmental features in English such as intonation seems to be neglected. Futhermore, teachers barely have accurate assessment systems to analyze pronunciation produced by students of English as a foreign language. Consequently, the students are directly dragged down to unintelligibility in speech production of spoken English.

Intonation plays crucial role in English. It is part of the language system. Intonation can convey grammatical meaning as well as the speaker's attitude. It will "tell" whether a person is making a statement or asking a question; it will also indicate if the person is confident, doubtful, shy, annoyed, or impatient (Dale \& Poms, 2005). It means that the 
appropriate use of intonation is necessary to convey message of the speaker correctly. Without realizing the use of intonation, listeners may get confused to what the speaker's intention. Intonation also helps language learners to get over serious intelligibility problems.

Intonation refers to the use of melody and the rise and fall of the voice when speaking. Kelly (2001) has a simillar statement, she describes the term of intonation as the way the voice goes up and down in pitch when we are speaking. Speakers produce melodies by changing the frequency of vibration of the vocal cords, mostly at the accented syllable. They recognize falling and rising tunes of different length - long fall and short fall, long rise and short rise - and combinations of these tunes (Kreidler, 2004). Meanwhile, Hart, Coiler, and Cohen (1992:02) have more technical defintion about intonation; it is the assemble of pitch variations in speech caused by the varying periodicity in the vibrations of the vocal cords.

English uses rising and falling pitches diffrently and has its own distinctive melody and intonation patterns. The main movements of pitch, within a tone unit, are called tones. In English, there are two tones; rise and fall or more accurately rise and fall intonation. English utterances are seldom spoken in a monotone. Speakers produce melodies of different kinds, with the voice rising and falling, and hearers perceive different melodies. Strangely, though, the tunes which the speaker produces are not exactly what the listener hears (Kreidler, 2004). This idea may refer to learners of English in Indonesia. Most of English language learners in Indonesia do not 'hear' intonation very well. It is because the learners have different perception in perceiving the intonation. Moreover, their knowledge about English intonation is inadequate. When they listen to speech, they are powerfully distracted from paying attention to pitch changes because they are struggling to understand sounds, vocabulary, and grammar. In fact, inappropriate pronunciation could change the mood in a sentence. For example, using the rising intonation in a declarative sentence (e.g they're leaving) would change the sentence to an interrogrative sentence (they're leaving?) which needs a clarification from the hearer.

Research on intonation has increased and led to series of approaches, including intonation as pragmatics resource, discourse intonation, and intonational meaning. Intonation as pragmatics resource in second language learning particularly, study about English intonation produced by non-native speakers of English has attracted much attention from some experts and always interesting. In this study, the researcher aims to discover the use of intonation in English declarative sentences produced by first semester of English Department 
students of Universitas PGRI Yogyakarta (UPY). Since the researcher is a pronunciation lecturer in the university, he intends to test his students in understanding English intonation and how they perceive English intonation then reveal the contour of intonation produced by the students in order to make an improvement in teaching English especially pronunciation.

\section{Methodology}

In this study, the researcher uses the contour approach and will be analyzing these contours: rise-fall, and fall-rise. To gain the contour data, This research applies soundwave diagrams and pitch graphs which are collected from every respondent through the process of listening and recording method. There are two steps in collecting the data, firstly, the students are asked to listen the sentence. secondly, the students are asked to produce what they exactly heard about the sentence while the researcher records them one by one. The model sentence is taken from English Pronunciation Made Simple written by Paulette Dale and Lillian Poms, published by Longman Pearson Education 2005. The model sentence is "Tim bought a new car". After the listening and recording process are done, the sounds are converted to soundwaves and pitch graphs using PRAAT free software. The soundwaves and pithc graphs are segmented word by word using PRAAT text grid to make the graphs easier to understand. The researcher then analyzes the movement of pitch so that the intonation can be drawn and seen to conclude the perception.

The respondents of this research are the first semester students of English Department of Universitas PGRI Yogyakarta. The researcher only chooses randomly three students as the respondents to represent the use of intonation in declarative sentence produced by non-native speakers. The three students come from different background. Since they are teachers to be, they should be able to pronounce English sentences correctly and manage to convey the actual meaning of each sentence.

\section{Discussion}

Teaching pronunciation requires great efforts and involves series of challenges. It is not only teaching how to pronounce every single word correctly but also how the words are spoken together and to make an intelligible communication in English.

\subsection{English Suprasegmental Features}

Communication in spoken English is organized by suprasegmental features. These suprasegmental features are simillar to musical signals. The reason is that for the purposes of teaching pronunciation, the teacher needs to understand these musical signals work. Kelly (2001:3) states that suprasegmental features, as the name implies, are features of speech 
which generally apply to groups of segments, or phonemes. The features which are important in spoken English are stress, intonation, and how sounds change in connected speech which is called the rhythm. Ladefoge (2010:243) adds, suprasegmental features are aspects of speech that involve more than single consonants or vowels. The principal of suprasegmental features are stress, length, tone, and intonation.

Meanwhile, Odgen (2009) defines suprasegmentals as properties of speech which extend over segments. Its features of speech include intonation, loudness, rhythm, voice quality and tempo. Suprasegmentals are aspects of speech which persist over several segments, such as duration, loudness, tempo (speed), pitch characteristics and voice quality. They are often thought of as the 'musical' aspects of speech. Suprasegmental is important in English, it is used for marking all kinds of meanings, in particular speakers' attitudes to what they are saying (or the person they are saying it to). Unquestionably, suprasegmental feature has significant role in English.

\subsection{Intonation Analysis}

Intonation has four function in communication, they are: (1) the structural function, which signals the grammatical or structural role of an utterance, determining, for example, whether it is a question, a statement, or an instruction, (2) the accentual function, which affects the prominence of a syllable, and thus plays a role in focusing stress on particular words in connected speech, (3) the attitudinal function, which function conveys the speakers' personal orientations towards what they say, or give us clues about how the speakers feel, whether they are uninterested, excited, or ironic, (4) the discourse function marks the turntaking processes in an exchange between speakers (Skandera \& Burleigh, 2005).

There are many different ways to characterise intonation, which is also called pitch contour or pitch movement. According to Kreidler (2001), there have been two approaches to the description of English intonation, a level approach and a contour approach. The levels approach is based on the assumption that the tune of any utterance can be described as a sequence of contrasting levels of pitch; almost universally, those who follow this approach consider that there are four such levels. The contour approach is based on the notion that speakers of the language react to the changes of pitch. This means intonation can be analysed by pitch contour or pitch movement. In this study, the writer only focuses on analysing the structural function which function is to determine the mood of a sentence by examining the pitch movement using PRAAT software. 


\subsection{Perception}

Richards and Schmidt (2002) describe perception as the recognition and understanding of events, objects, and stimuli through the use of senses (sight, hearing, touch, etc.). They divide several different types of perception. They distinguish perception into three: (1) visual perception, it is the perception of visual information and stimuli, (2) auditory perception, it is the perception of information and stimuli received through the ears. Auditory perception requires a listener detect different kinds of acoustic signals, and to judge differences between them according to differences in such acoustic characteristics as their frequency, amplitude, duration, order of occurrence, and rate of presentation and, (3) speech perception, it is the understanding or comprehension of speech. Meanwhile, Kreidler (2001) makes more simple definition about perception, he argues that perception is sort of information about a language do people have stored in the unconscious part of their brains that makes it possible for them to recognize what they have heard. It can be drawn that in the case of teaching pronunciation, students might be confused or do not hear clearly about what sentences they heard.

\subsection{English Declarative Sentence and Intonation Produced by Learners of English}

A declarative sentence is a sentence which is in the form of statement (Richards and Schmidt, 2002). It states a fact and can be used to describe an action and statement. A declarative sentence does not convey emotional involvement on the part of the speaker and it remains neutral. Generally, English speakers use the falling intonation in declarative sentences. The model of English declartive sentence is characterized by a single intonational pattern only; falling pitch at the end of the sentcence.

Intonation is the linguistic use of particular contours in the production of speech. These contours can be described using labels that refer to their shapes such as 'fall' and 'rise'. English has several basic intonation contours. However, there are many more possible variations that change with a speaker's intended meaning, attitude and emotional state of mind. Without realizing it, we can confuse the listeners by using incorrect English intonation patterns. If the voice rises when it should fall, it will change a declarative sentence to a question. If the voice stays level when it should either rise or fall, it will sound bored or uninterested. It will also confuse the listeners into thinking whether is it an unfinished sentence or question.

There are many types of declarative sentences one of them is a straightforward statement. The researcher uses the model sentence Tim bought a new car which is taken from 
English Pronunciation Made Simple. The audio file from native speaker is also taken from the book. This picture bellow illustrates the acceptable contour of an English declarative sentence produced by English native speaker.

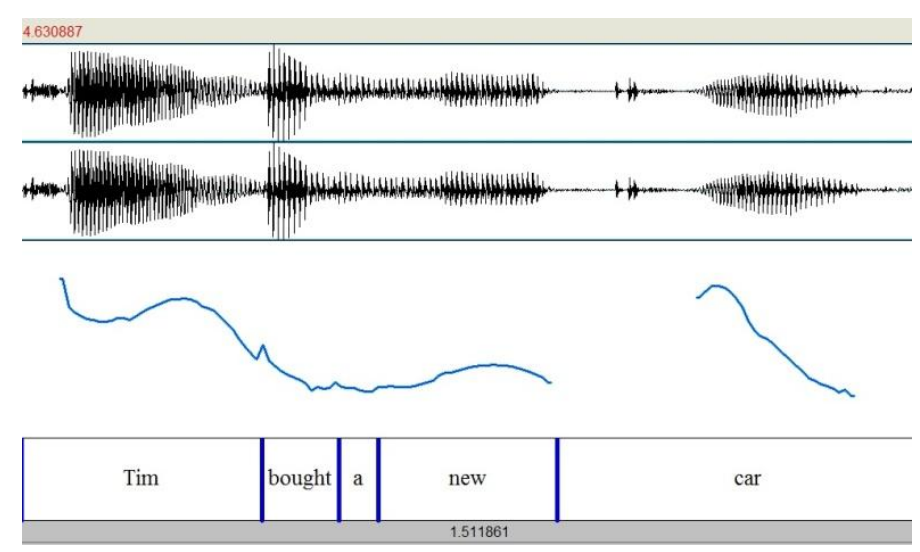

Picture 1

An interrogative sentence produced by native speaker.

Picture 1 shows that there is a falling pitch at the end of the sentence. The line graph represents the movement of pitch. From picture 1, it is noticable that there is a fall contour at the end of the sentence or at the final sound. It means that the native speaker uses the falling intonation in a declarative sentence which indicates that the speaker is making a statement. If the contour is different, then the meaning is different. Falling intonation in a declarative sentence is acceptable in English. Most English speakers would say that the sample sentence in this research produced this way express straightforward agreement.

In contrast, the learners of English did not perceive and produce the similar intonation on the same sentence although they had listened to the native (correct) version before they produce it. The next following figures are declarative sentence produced by respondents who are first semester students of English Department.

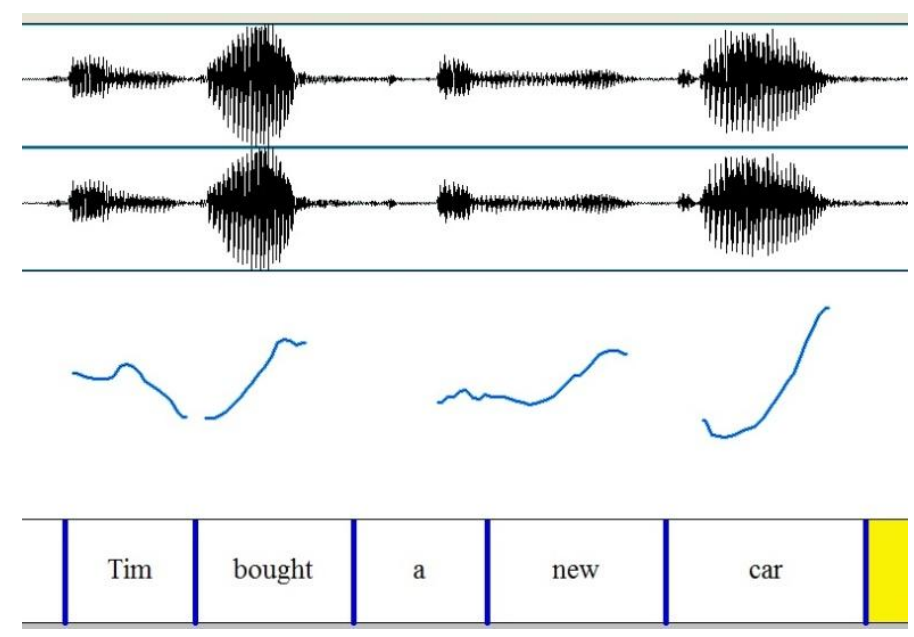

Picture 2

The same interrogative sentence produced by respondent 1 
Picture 2 shows that respondent 1 rises the pitch at the end of the sentence. It can be seen from the word car which has been given the highest picth. This intonation contour does not correspond to the contour of a declarative sentence.

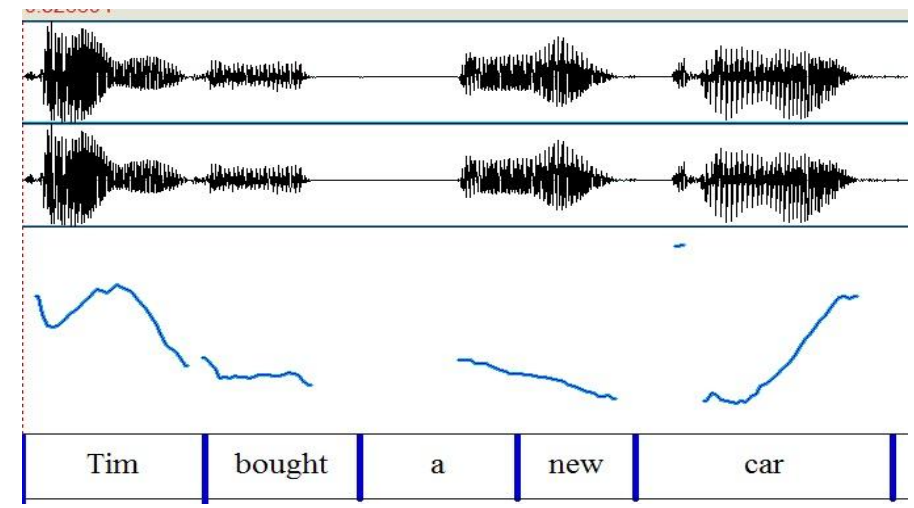

Picture 3

The same interrogative sentence produced by respondent 2

Picture 3 demonstrates that respondent 3 rises the intonation at the end of the declarative sentence although at the begining of the sentence he give stress on the word Tim. This automatically changes the mood of the declarative sentence into an interrogative sentence.

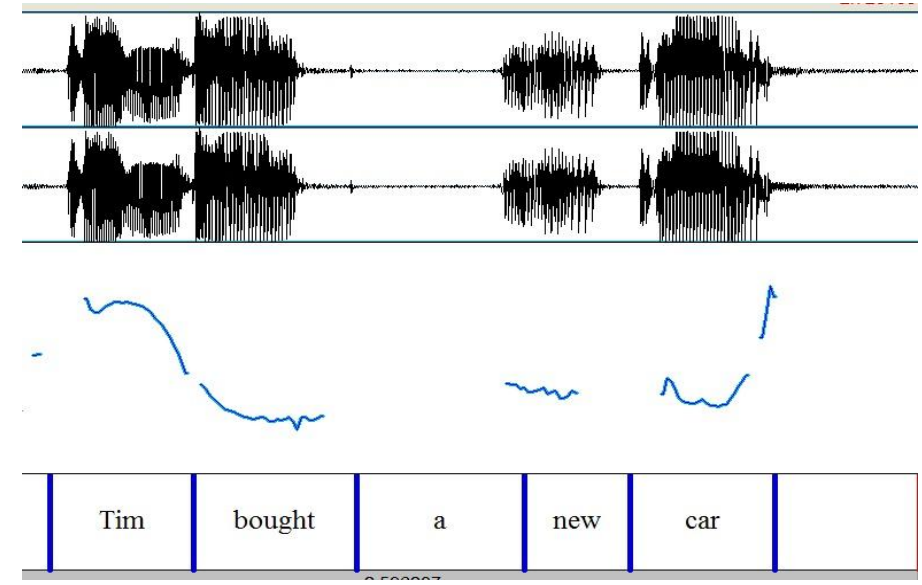

Picture 4

The same interrogative sentence produced by respondent 3

Picture 4 shows that there is a rise contour at the begining of the sentence, more specifically the word Tim then the contour tend to level off although there is a high pitch on the word or the article $a$ but gradually rises at the end of the sentece. It can be stated that the contour of the declarative sentence produced by respondent 3 does not indicate that the sentence is a declarative sentence.

Overall, It can be clearly seen that the graphs (picture 2, picture 3 and picture 4) demonstrate different intonation from native speaker. Students are speaking the same sentence using different intonation. It is immediately obvious that the contours of the pitch rise at the end of the declarative sentence. It is proven by the rise in the end of the line graphs. 
It means that the students use rise intonation at the end of the declarative. Correspondingly, using rising intonation in English declarative sentence would automaticaly change the mood of the sentence into an interrogative sentence. It is because this intonation sounds like a yes/no question that demands upcoming respons or disagreement. It should also be noted that using an upward pitch at the end of declarative sentences indicate that the speaker is doubtful or uncertain about what he or she is saying (Dale \& Poms, 2005). In addition, Kreidler also states that a rising contour may indicate the speaker's expectation of some response from the listener, or it may suggest a contradiction of what has been said previously; a short rise is a signal to begin a conversation or a vocal gesture indicating willingness to participate in a conversation. It is obvious that the intonations in picture 2,3 and 4 have meaning that the speaker wanted to ask clarification from the hearers about Tim and his new car.

\section{Conclusion}

In conclusion, this research only draws the general intonational contour of English declarative sentence produced by English Department students in Universitas PGRI Yogyakarta. This research illustrates that English Department students produce error intonation in pronunciation. The result of this research shows that learners of English have a tendency to be frivolous in intonation and unable to perceive English intonation. It is proven by their production of English intonation, the students tend to rise the pitch at the end of declarative sentence which automatically changes the mood of the sentence to an interrogrative sentence. In addition, this research also illustrates that students of English have inadequate knowledge about suprasegmental features in English particularly intonation. It indicates that teaching English especially pronunciation can be quite difficult due to the students' perception about intonation. This project is only preliminary reseach which still needs further research related to use of English intonation of non-native speakers. This research would also be a worthwhile and an interesting topic for future research.

\section{Bibliography}

Dale, P \& Poms, L. 2005. English Pronunciation Made Simple. New York: Pearson Education.

Baker, A \& Goldstein, S. 2001. Pronunciation Pairs: An Introduction to Sound of English. Cambridge: Cambridge University Press.

Handcock, Mark. 2002. English Pronunciation in Use. Cambridge: Cambridge University Press. 
Harmer, J. 2001. The Practice of English Language Teaching. Essex: Pearson Education Limited.

Kreidler, Charles W. 2004. The Pronunciation of English: A Course Book. Second Edition. Victoria: Blackwell Publishing.

Ladefoge, Peter. 2006. Course in Phonetics. Los Angeles. Thomson Learning.

Odgen, Richard. 2009. An Introduction to English Phonetics. Edinburgh University Press.

Richards, Jack C \& Schmidt, Richards. Longman Dictionary of Language Teaching and Applied Linguistics. London: Pearson Education

Roach, P. 2009. English Phonetics and Phonology: A practical course. Cambridge: Cambridge University Press

Scarcella, R. \& Oxford, R.L. 1994. Second language pronunciation: State of the art in instruction. System. 22(2), 221-230.

Skandera, P \& Burleigh, P. 2005. A Manual of English Phonetics and Phonology. Tubingen: GNV 